\title{
Five Doubly Unsaturated Metabolites of Valproic Acid in Urine and Plasma of Patients on Valproic Acid Therapy ${ }^{1}$ )
}

\author{
By W. Kochen, H. P. Sprunck \\ Klinikum der Universität Heidelberg, Kinderklinik
}

\section{B. Tauscher and M. Klemens}

Organisch-Chemisches Institut der Universität Heidelberg

(Received June 20, 1983/January 30, 1984)

Summary: The urine and plasma of epileptic patients receiving therapeutic doses of valproic acid (2-propylpentanoic acid) was found to contain five doubly unsaturated metabolites of valproic acid, which were identified as their trimethylsilyl derivatives by GC/MS. A series of reference substances was synthesized but only two of them were identical with native metabolites: 2(2-propenyl)-4-pentenoic acid $\left(=4.4^{\prime}\right.$-diene) and E-2propyl-2.4-pentadienoic acid (E-2.4-diene). The mass-spectra of the five native metabolites are given. Preliminary quantitative data obtained from four groups of patients indicate increased formation of doubly unsaturated metabolites when valproic acid-induced side-effects are present, and in cases of fatal hepatic failure. The $4.4^{\prime}$-diene has hitherto been found only in fatal cases with hepatic injury. Quantitative data are presented as $\%$ of the sum of valproic acid plus all its detected metabolites.

Fünf zweifach ungesättigte Metabolite der Valproinsäure in Urin und Plasma von epileptischen Patienten unter Behandlung mit Valproinsäure

Zusammenfassung: In Urin und Plasma von epileptischen Patienten unter Behandlung mit Valproinsäure (2Propylpentansäure) konnten insgesamt fünf zweifach ungesättigte Metabolite der Valproinsäure als Trimethylsilyl-Derivate durch GC/MS identifiziert werden. Eine Reihe von Referenzsubstanzen wurde synthetisiert, aber nur zw̄ei von ihnen waren mit nativen Metaboliten identisch: 2(2-Propenyl)-4-pentensäure (= 4.4'-dien) und E-2-Propyl-2.4-pentadiensäure (= E-2.4-dien). Die Massenspektren der fünf nativen Metabolite werden angegeben. Vorläufige quantitative Ergebnisse aus vier Gruppen von Patienten zeigen eine erhöhte Bildung von żweifach ungesättigten Mètaboliten bei Valproinsäure-induzierten Nebenwirkungen und bei letalen Leberschäden. Das 4.4'-Dien konnte bisher nur bei Todesfällen mit Leberintoxikation nachgewiesen werden. Die quantitativen Werte werden in \% der Summe aus Valproinsäure und allen nachgewiesenen Metaboliten angegeben.

\section{Introduction}

Valproic acid (2-propyl-pentanoic acid) is a widely used antiepileptic drug extremely effective against absence and generalized tonic-clonic seizures (1). It was commonly believed to be relatively free from adverse side-effects. During recent years, however,

1) Supported by Deutsche Forschungsgemeinschaft (programme "Research in Epilepsy"). it has been incriminated as the cause of severe, and in some instances fatal hepatic injuries (2). Throughout the world, a total of 68 fatal cases have been recognized (3). Early calculations revealed frequencies of 1:10000-1:20000 (4) and 1:50000 (5). The pathogenesis of this fatal hepatic failure is not understood and the first case in which valproic acid metabolism could be studied was published by Kochen et al. (6). The prominent feature in this patient was the 
abnormally increased formation of mono- and di-unsaturated metabolites of valproic acid. Therefore it seems necessary to further investigate this new group of doubly unsaturated metabolites, which we reported earlier (7).

There are substantial problems in the synthesis of doubly unsaturated derivatives of valproic acid, because the introduction of two double bonds results in 14 different stereoisomers. Moreover, if carbon 2 in valproic acid becomes chiral then an additional 4 enantiomers must be taken into consideration: Both stereoisomers of the $3.4^{\prime}$-diene form enantiomers ( $D$ - and $L$-2(2-propenyl)-3-trans-pentenoic acid and $D$ - and $L-2$ (2-propenyl)-3-cis-pentenoic acid). In the case of the 3.3'-diene only 2(1-trans-propenyl)-3-cis-pentenoic acid may be expected to form enantiomers.

In the present work, we report the detection of a total of five doubly unsaturated metabolites of valproic acid in patients on valproic acid therapy. Preliminary quantitative data indicating the possible pathological importance of this new group of metabolites are also presented.

\section{Methods and Materials \\ Valproic acid derivatives}

The syntheses of doubly unsaturated valproic acid derivatives have been described by Klemens (8).

All these compounds have not been described in literature except the $4.4^{\prime}$-diene $(9,10)$.

2(2-Propenyl)-4-pentenoic acid (4.4'-diene) was obtained by malonic ester synthesis using allylbromide, followed by saponification and decarboxylation.

2(2-Propenyl)-3-pentenoic acid (3.4'-diene): Knoevenagel-reaction of propionaldehyde and diethylmalonate, alkylation of the propylidenediethylmalonate with 1-bromopropene-2, saponification and decarboxylation.

2(2-Propenyl)-2-pentenoic acid (2.4'-diene): acylation of diethylmalonate with propionylchloride, alkylation with allylbromide, reduction by $\mathrm{NaBH}_{4}$, decarboxylation, dehydration and saponification.

2-Propyl-2.4-pentadienoic acid (2.4-diene) was obtained by a Wittig reaction with 2-bromoethylpentanoate and acrolein.

2(1-Propenyl)-2-pentenoic acid (2.3'-diene): nucleophilic acylation of 1-bromopropane with umgepoltem crotonaldehyde followed by saponification.

Mass-spectra of the synthetic diene compounds

The synthetic products were purified by common methods. The trimethylsilylesters of the acids were analysed by GC/MS.

Determination of valproic acid metabolites by GC/MS Sample preparation

$50-200 \mu$ l of the sample (urine, plasma etc.) were added to $200 \mu \mathrm{l}$ of $0.5 \mathrm{~mol} / 1 \mathrm{NaH}_{2} \mathrm{PO}_{4}$ buffer $\mathrm{pH} 5.0$ containing 3 internal stan- dards $(1 \mu \mathrm{g}$ each of di-n-butylacetic acid, phenylbutyric acid and $\mathrm{C}_{19}$-alkane) and $20 \mu \mathrm{l}$ glucuronidase/arylsulphatase (Serva, Heidelberg). After incubation of the mixture for $3 \mathrm{~h}$ at $37^{\circ} \mathrm{C}$ the metabolites were extracted with ethyl acetate $(3$ times; $0.5 \mathrm{ml})$. The volume of the combined organic phases was reduced to about $20 \mu \mathrm{l}$ (not to dryness!) under a stream of dry nitrogen. The acids were silylated with $10 \mu \mathrm{l}$-methyl-trimethylsilyl-trifluoracetamide (MSTFA, Machery \& Nagel, Düren).

\section{Gas-chromatographic conditions}

$50 \mathrm{~m}$ capillary glass column SE-54 (Jaegi, Trogen, Switzerland), split $1: 20$, temperature programme $75^{\circ} \mathrm{C}(10 \mathrm{~min}), 4^{\circ} \mathrm{C} / \mathrm{min}$ up to $200^{\circ} \mathrm{C}, \mathrm{P}_{\mathrm{i}} 1.2$ bar (He). Mass-spectrometer DuPont 21-492 B, open interface combination, ionisation energy $70 \mathrm{eV}$, ion source temperature $250^{\circ} \mathrm{C}$, interface $210^{\circ} \mathrm{C}$.

\section{Quantification}

Valproic acid, its metabolites and the internal standards were mass-fragmentographically determined by means of $\mathrm{M}^{+}-15$ mass-ions. Calibration samples were prepared as above. Quantification of diene $/ 3$ and diene/ 4 was performed by using two other synthetic diene derivatives with identical intensities of $\mathrm{m} / \mathrm{z} 197$ and 122 as in the native metabolites.

\section{Results}

\section{Synthetic diene compounds}

GC/MS investigations demonstrated that the synthesized products consisted of mixtures of isomers, which we have numbered $/ 1, / 2$, etc. according to their increasing retention time. The isomers were not isolated and the stereo-chemical structure remains unknown. Table 1 presents the mass-ions and their intensity in \% base-peak. The most intensive massion above $\mathrm{m} / \mathrm{z} 100$ was selected for the base-peak; the fragments below $\mathrm{m} / \mathrm{z} 90$ were considered to be of minor importance, and were therefore ignored. In investigating new syntheses for diene compounds without a terminal double bond, we obtained a series of doubly unsaturated valproic acid derivatives which were characterized by GC/MS. Three of these (diene-S5, diene-S6, and diene-S7) are also listed in table 1.

\section{Native diene metabolites}

Synthetic hydroxylated valproic acid derivatives (hydroxylated in position 5, 4, 3 and 2) were added to control samples of urine and plasma, and the samples prepared for GC-analysis as described in methods. Mass-fragmentographic analysis of hydroxylated valproic acid derivatives did not generate detectable unsaturated derivatives, i.e. dehydration does not occur under the conditions used.

As an example figure 1 presents the mass-fragmentographic chromatogram of a urine sample from an epileptic and extremely dystrophiic patient treated 
Tab. 1. Synthetic diene compounds of valproic acid and the EI mass-spectra of their trimethylsilyl derivatives. The most intense mass-ion above $\mathrm{m} / \mathrm{z} 100$ was taken as base-peak (100\%). Mass-ions below $\mathrm{m} / \mathrm{z} 90$ were abandoned. For further details of dienes S5, S6 and 57 see text.

2(2-Propenyl)-4-pentenoic acid (4.4'-diene)

2(2-Propenyl)-3-pentenoic acid, 1st isomer (3.4'-diene/1)

2(2-Propenyl)-3-pentenoic acid, 2nd isomer (3.4'-diene/2)

Diene-S11: additional diene from synthesis of 3.4'-diene

2(2-Propenyl)-2-pentenoic acid, 1st isomer (2.4'-diene/1)

2(2-Propenyl)-2-pentenoic acid, 2 nd isomer (2.4'-diene/2)

2-Propyl-2.4-pentadienoic acid, 1 st isomer (2.4-diene/1)

2-Propyl-2.4-pentadienoic acid, 2 nd isomer (2.4-diene/2)

2(1-Propenyl)-2-pentenoic acid, 1st isomer (2.3'-diene/1)

Diene-S5

Diene-S6

Diene-S7
$197(100), 94(64), 117(37), 171(34), 111(23), 169(20), 122(15), 105(8)$

$197(100), 155(29), 81(26), 171(22), 94(20), 169(17), 170(16), 117(16), 212(12)$, $156(12), 111(8), 122(5), 157(5)$

171 (100), $197(68), 117(49), 156(35), 95(20), 125(18), 129(13), 111(11), 112(10)$, $212(8), 155(7), 143(7), 122(5), 118(5)$

$197(100), 212(74), 122(20), 96(10), 123(10), 183(8), 167(7), 156(6), 107(6)$, $110(5)$

$197(100), 94(50), 117(34), 155(30), 171(28), 111(22), 169$ (17), $122(16), 170(14)$, $156(14), 129$ (11), 212 (11)

197 (100), $122(73), 212(70), 123$ (39), 93 (22), 107 (17), 95 (17), 167 (17), 124 (11), $181(10), 183(9), 155(5), 125(5)$

197 (100), 183 (97), 122 (79), 123 (35), 95 (23), $153(9), 155(8), 169(7), 184$ (7), $117(6)$.

$122(100), 197$ (75), $123(50), 183(31), 212(25), 196(12), 107$ (10), 181 (7), 167 (7), $155(7), 111(5), 169(4)$

197 (100), $122(45), 212(40), 183(40), 123(30), 110(13), 95$ (12), $196(10), 152(10)$, $124(10), 167(8)$

$212(100), 197(96), 122(88), 93(22), 167(18), 123(15), 181(14), 95(13), 107(10)$, $101(8), 115(6), 173(6), 117(5), 112(4)$

122 (100), 197 (89), 212 (85), 147 (42), 95 (35), 140 (21), 167 (14), 181 (9), 107 (8), $169(8), 157(7), 111(6), 131(6), 117(4)$

197 (100), 212 (40), $122(31), 117(15), 129(14), 133(11), 123(9), 183(6), 156(6)$, $184(5), 169(5)$ with valproic acid. The usual mono-ene metabolites 2-propyl-3-pentenoic acid (3-ene) and 2-propyl-2pentenoic acid ( $\mathrm{Z}$ - and $\mathrm{E}-2$-ene) (see arrow 2, 3a and $3 \mathrm{~b}$ ), the oxidized metabolites (see arrow 8-12), and three doubly unsaturated metabolites E-2-propyl-2.4.-pentadienoic acid (= E-2.4-diene, diene/1), diene $/ 2$, and diene/3 (see arrow 4-6) are all clearly demonstrated. Due to their low concentration it is usually impossible to detect them on the basis of the total ion current (TIC) alone, and especially diene/3 is often hidden in the overlapping urea peak. Removal of urea by urease before extraction remarkably facilitates the detection of diene/3. Mass-spectra of the diene metabolites were obtained from urine samples containing elevated amounts of the compounds concerned. The typical mass-fragmentographic ions of the trimethylsilyl derivatives are the molecular ion $\mathrm{m} / \mathrm{z} 212$ and the $M-15$ mass $\mathrm{m} / \mathrm{z} 197$.

The mass spectrum of diene/ 1 trimethylsilyl derivative (arrow 4 in fig. 1) is given in figure $2 \mathrm{a}$ and agrees well with that of the second isomer from the synthesis of 2-propyl-2.4-pentadienoic acid trimethylsilyl derivative (see fig. 2b). The retention time of the native product is identical with that of the synthetic isomer characterized by the higher retention time (compare fig. 8). The $\mathrm{M}-15$ mass ion of the native product was determined at $\mathrm{m} / \mathrm{z} 197.0945$ (theoretical value 197.0998). In view of the higher retention time of this isomer we assume that it has the following structure: E-2-propyl-2.4-pentadienoic acid trimethylsilyl derivative<smiles>C=CC=C(CCCC)C(=O)OC</smiles>

The trans position of the carboxylic and the ethylene group may also be derived from the stereoselective course of the synthesis (11). 


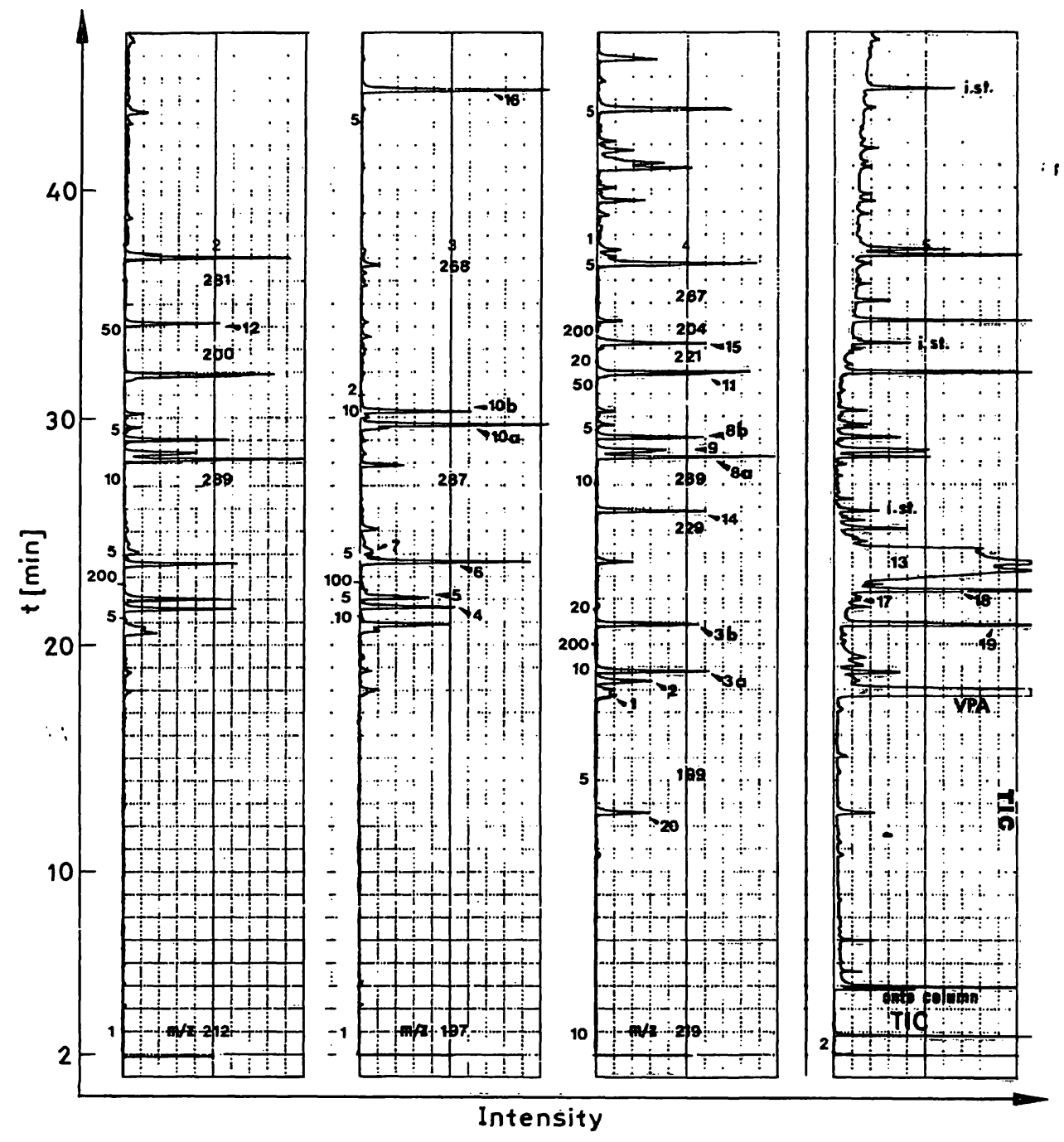

Fig. 1. GC/MS chromatogram of a hydrolysed urine sample of a patient treated with valproic acid (VPA). Mass-ions are given in the 3 channels, attenuation on the left side of each channel. Typical mass-ions of the metabolites as trimethylsilyl derivatives are indicated by arrows.

TIC = total ion current.

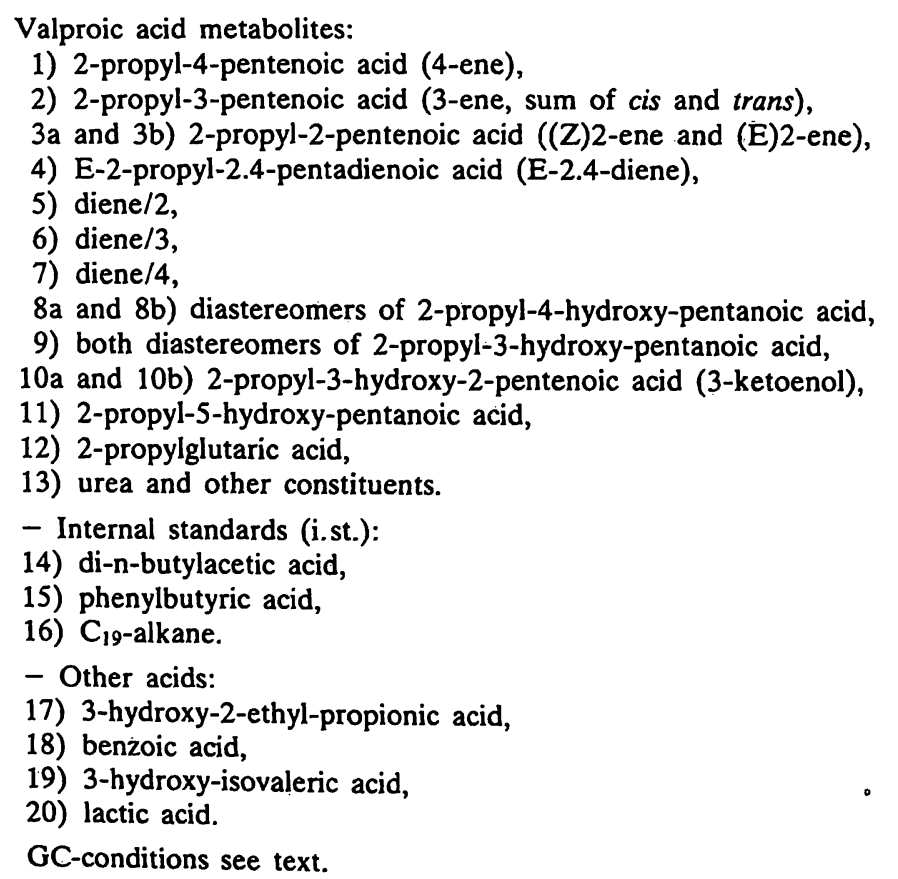

Valproic acid metabolites:

1) 2-propyl-4-pentenoic acid (4-ene)

$3 \mathrm{a}$ and $3 \mathrm{~b})$ 2-propyl-2-pentenoic acid ((Z)2-ene and $(\mathrm{E}) 2$-ene),

4) E-2-propyl-2.4-pentadienoic acid (E-2.4-diene),

5) diene/2,

6) diene/3,

$8 \mathrm{a}$ and $8 \mathrm{~b}$ ) diastereomers of 2-propyl-4-hydroxy-pentanoic acid,

9) both diastereomers of 2-propyl-3-hydroxy-pentanoic acid,

10a and 10b) 2-propyl-3-hydroxy-2-pentenoic acid (3-ketoenol),

13) urea and other constituents

- Internal standards (i.st.):

14) di-n-butylacetic acid

15) phenylbutyric acid

17) 3-hydroxy-2-ethyl-propionic acid,

18) benzoic acid,

20) lactic acid.

GC-conditions see text. 

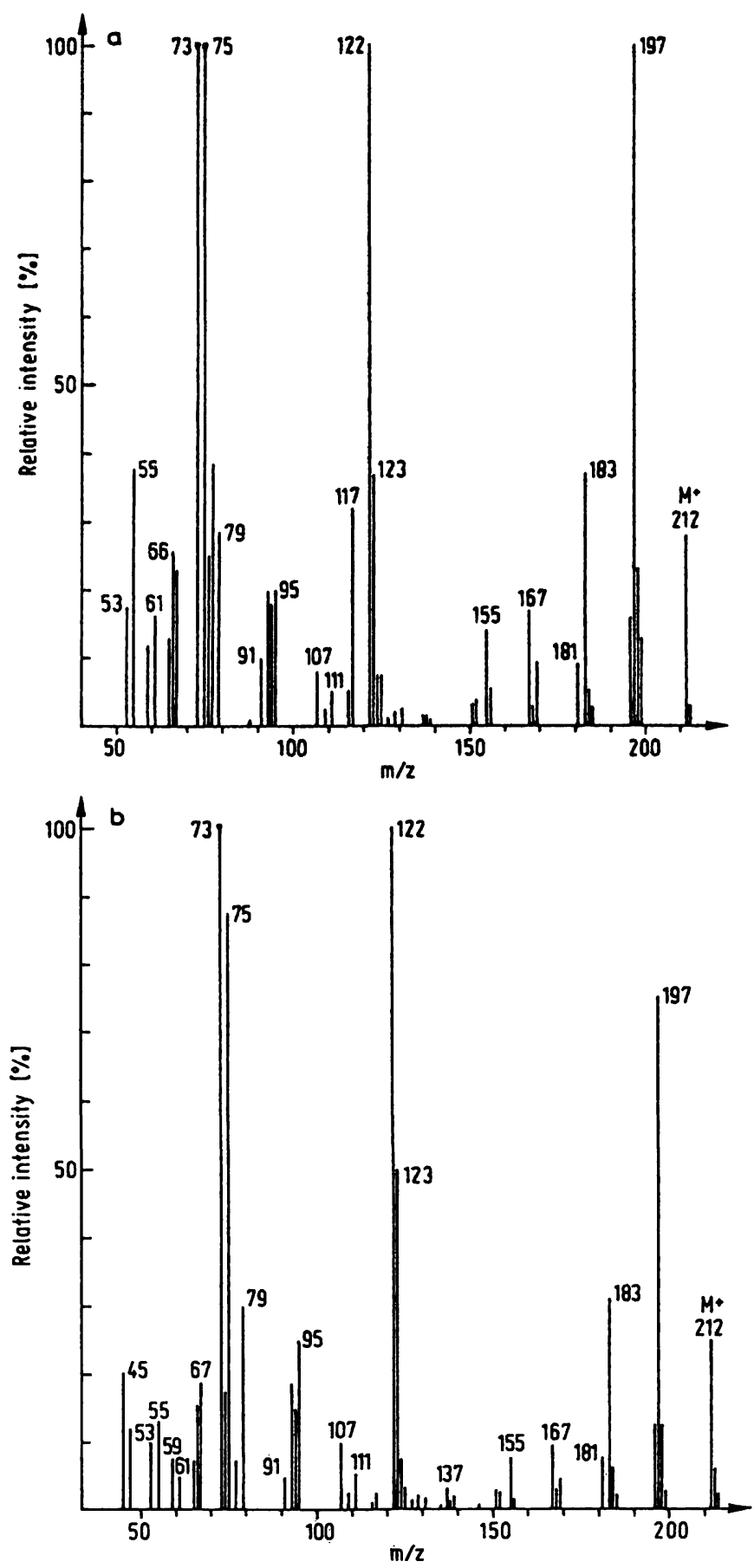

Fig. 2. Mass-spectrum of

a) native E-2-propyl-2.4-pentadienoic acid (diene/1, trimethylsilyl derivative),

b) synthetic 2 -propyl-2.4-pentadienoic acid trimethylsilyl derivative (second isomer with higher retention time).

The mass-spectrum of diene/ 2 trimethylsilyl derivative (see arrow 5 in fig. 1 ) is given in figure 3 and is likewise characterized by the base-peak of $\mathrm{m} / \mathrm{z} 122$ as in E-2-propyl-2.4-pentadienoic acid trimethylsilyl derivätive (= diene/1). Exactly defined reference compounds are not available for either diene $/ 2$ or the diene metabolites discussed in the following. As figure 8 indicates all defined synthetic diene com-

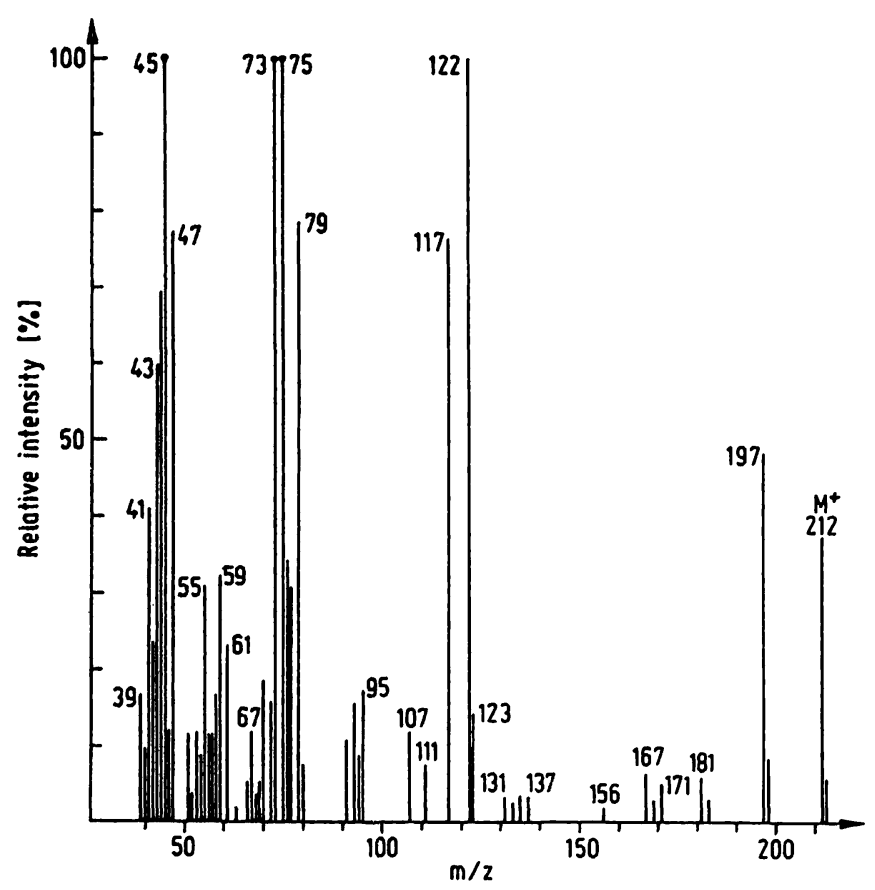

Fig. 3. Mass-spectram of native diene/2 trimethylsilyl derivative.

pounds have shorter retention times. Only the synthetic products, diene-S5, diene-S6, and diene-S7 were found in small amounts as by-products in the synthesis of the 2.3'-diene and 3.3'-diene. Their mass-spectrometric data indicating a diene structure are therefore also listed in table 1 . The positions of the two double bonds in these three unsaturated products were not elucidated.

In spite of the identical retention time of diene/ 2 and the synthetic product diene-S5 their mass-spectra differ with respect to the relative intensities of the typical mass-ions.

The mass-spectrum of diene $/ 3$ trimethylsilyl derivative (fig. 4) is also in accordance with the presence of a doubly unsaturated metabolite as confirmed by high-resolution of the molecular ion (found $\mathrm{m} / \mathrm{z}$ 212.1195, theoretical value 212.1232).

The following two doubly unsaturated metabolites were detected and identified in fatal cases $(6,12)$, whereas they are unknown in patients without complications. Identification of 2(2-propenyl)-4-pentenoic acid (4.4'-diene) was possible only because the samples of the patient concerned (6) contained a very low concentration of valproic acid. As demonstrated in figure 5 , the trimethylsilyl derivatives of the synthetic 4.4'-diene, 4-ene and valproic acid are eluted very close together under the gas chromatographic conditions used, so that in the presence of an excess of valproic acid it is difficult to detect these 
two metabolites. The mass-spectrum of the native $4.4^{\prime}$-diene trimethylsilyl derivative is given in figure 6 and agrees well with that of the synthetic product. The relative intensity of $\mathrm{m} / \mathrm{z} 122$ amounts only to about $15 \%$ and the molecular ion $\mathrm{m} / \mathrm{z} 212$ ist not higher than $10 \%$ of the base-peak $\mathrm{m} / \mathrm{z} 197$, whose exact mass was determined at 197.1092 (theoretical value 197.0998).

The 4.4'-diene is not present in the sample shown in figure 1, but the 4-ene (arrow 1) is present in more than trace amounts. This metabolite is not normally detectable in urine or plasma, and its existence was confirmed by the characteristic mass-ions $\mathrm{m} / \mathrm{z} 172$ and 185 and by the addition of the authentic reference compound. The mass-spectrum of the 4-ene has been published in 1.c. (6).

The last of the five diene metabolites has the highest retention time and is termed diene/4. As in the case of diene/ 3 , it may be overlapped by urea. The mo- lecular ion was determined at $\mathrm{m} / \mathrm{z} 212.1300$. The typical mass-ions indicate again a doubly unsaturated metabolite, although an authentic reference substance is still lacking (mass-spectrum fig. 7). In figure 1 traces of diene/4 were also detected by recording $\mathrm{m} / \mathrm{z} 122$.

A comparison of the retention indices of both the synthetic and the native diene compounds is given in figure 8 . The synthetic products, diene-S5, diene-S6 and diene-S7 are not defined in respect to the position of the two double bonds and they are listed only on the basis of their increasing retention times, which are in the same order as those of the native diene-metabolites, diene $/ 2$, diene $/ 3$, and diene $/ 4$. For analytical purposes the exact relative retention times of the trimethylsilyl derivatives of valproic acid, the five diene metabolites, and the mono-ene metabolites are summarized in table 2 . The gas chromatographic peaks are more or less contaminated by

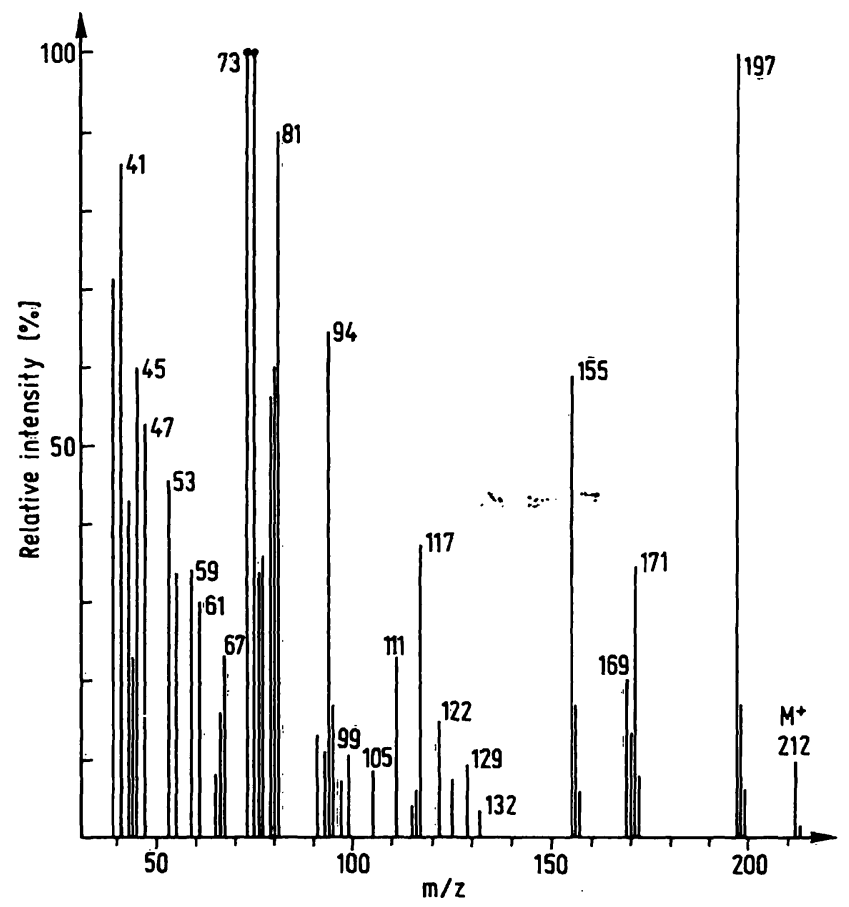

Fig. 6. Mass-spectrum of native 2(2-propenyl)-4-pentenoic acid (4.4'-diene) trimethylsilyl derivative.

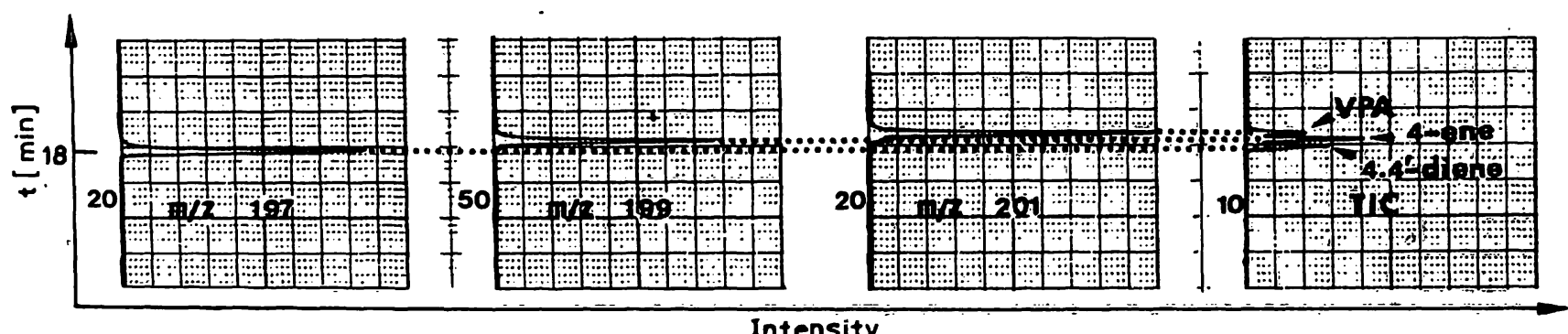

Intenșity

Fig. 5. GC/MS chromatogram of synthetic valproic acid (VPA), 2-propyl-4-pentenoic acid (4-ene), and 2(2-p.ropenyl)-4-pentenoic acid, (4.4'-diene) as trimethylsilyl derivatives.

GC-conditions as in figure 1 . TIC $=$ total ion current. 


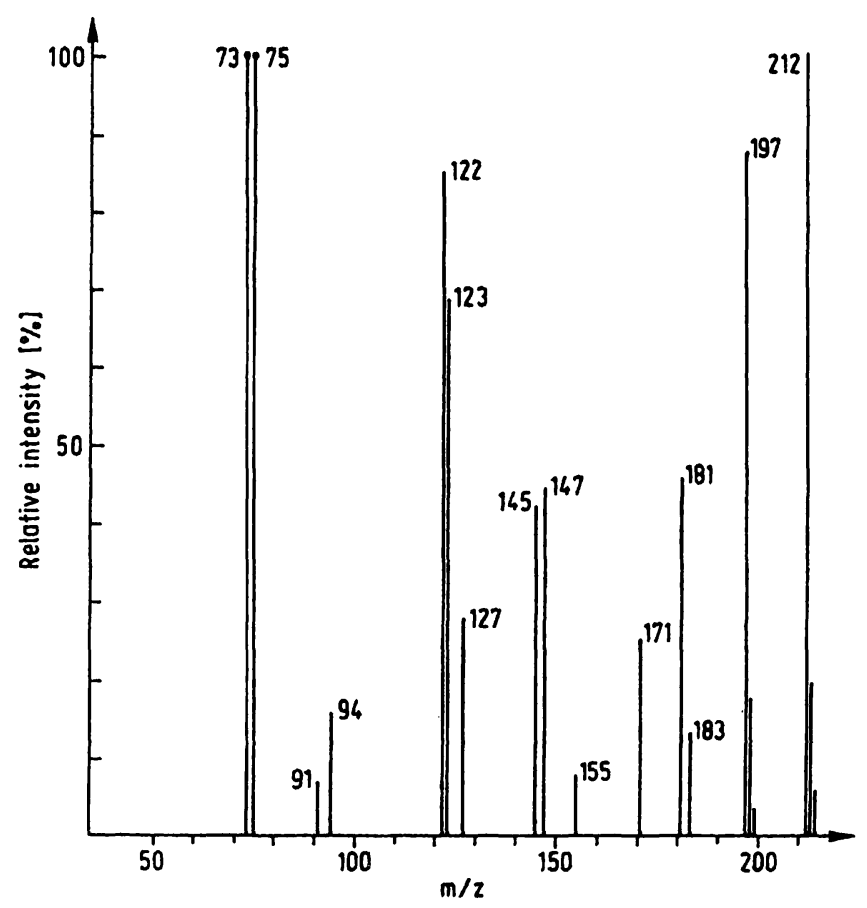

Fig. 7. Mass-spectrum of native diene/4 trimethylsilyl derivative.

other urinary acidic constituents which, depending on their concentration, may completely overlap these valproic acid metabolites. The commonly found contamination products are also listed in table 2 .

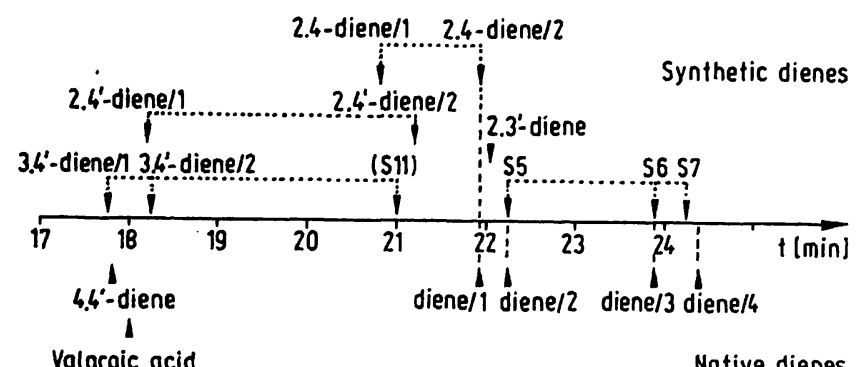

Fig. 8. Retention indices of synthetic and native diene derivatives of valproic acid (VPA) as trimethylsilyl derivatives. GCconditions as in figure 1.

Concentration of the diene metabolites in patients on valproic acid therapy

Preliminary quantitative results for diene metabolites found in four groups of patients (adults without side-effects, children with reversible side-effects such as vomiting, drowsiness, anorexia etc, one fatal case with hepatic failure (6), and children without complications in therapy) are given in table 3 in \% of the sum of valproic acid plus all detected and quantified metabolites $(=100 \%)$. These percentages have proved to be more informative than the absolute quantitative data of the single metabolites. Besides

Tab. 2. Trimethylsilyl derivatives of the mono-ene- and diene metabolites of valproic acid: retention times $\left(R_{1}\right)$ are related to the internal standards, di-n-butylacetic acid trimethylsilyl derivative, phenylbutyric acid trimethylsilyl derivative, and $C_{\mid y-a l k a n e}$. The contamination products listed are usually observed together with the metabolites in the urinary samples under the GC-conditions used (see method); TMS = trimethylsilyl derivative.

\begin{tabular}{lll}
\hline Compound & $\mathbf{R}_{\mathbf{t}}$ & Contamination by \\
\hline 4,4'-diene & $0.679 / 0.529 / 0.395$ & \\
4-ene & $0.687 / 0.535 / 0.400$ & Overlapped by valproic acid \\
Valproic acid & $0.698 / 0.545 / 0.405$ & Cresol TMS, 3-hydroxy-propionic acid TMS \\
3-ene & $0.712 / 0.554 / 0.414$ & 3-Hydroxy-n-butyric acid TMS \\
(Z) 2-ene & $0.727 / 0.566 / 0.423$ & 2-Hydroxy-3-methyl-butyric acid TMS \\
(E) 2-ene & $0.809 / 0.630 / 0.471$ & 3-Hydroxy-isovaleric acid TMS \\
E-2,4-diene & $0.838 / 0.655 / 0.490$ & (En-C \\
diene/2 & $0.852 / 0.667 / 0.500$ & 2-Ethyl-3-hydroxy-propionic acid TMS \\
diene/3 & $0.914 / 0.714 / 0.534$ & Urea TMS \\
diene/4 & $0.940 / 0.736 / 0.552$ & (Urea TMS), PO 4 TMS \\
\hline
\end{tabular}

Tab. $\dddot{3}$. Concentration of diene metabolites of valproic acid in patients on valproic acid therapy. Values are given in $\%$ of the sum valproic acid plus all determined mẹtabolites. For details see text.

\begin{tabular}{|c|c|c|c|c|c|c|c|c|}
\hline \multirow[t]{2}{*}{ Mẹtabolite } & \multicolumn{2}{|c|}{ Adult patients $(n=5)$} & \multicolumn{2}{|c|}{$\begin{array}{l}\text { Reversible side-effects } \\
\text { children }(n=3)\end{array}$} & \multicolumn{2}{|c|}{$\begin{array}{l}\text { Hepatic failure } \\
\text { fatal case (6) }\end{array}$} & \multicolumn{2}{|c|}{$\begin{array}{l}\text { Children }(n=6) \\
\text { without side-effects }\end{array}$} \\
\hline & Plạsma & Urine & Plasma & Urine & Plasma & Urine & Plasma & Urine \\
\hline $\begin{array}{l}\text { 4.4'-diene } \\
\text { E-2,4-diene } \\
\text { diene } / 2 \\
\text { diene } / 3 \\
\text { diene } / 4\end{array}$ & \begin{tabular}{l}
\multicolumn{2}{c}{0} \\
0.1 \\
$0=0.02$ \\
$0.5-4.9$ \\
$0-0.1$
\end{tabular} & $\begin{array}{ll} & 0 \\
0.05-0.1 \\
0 & -0.1 \\
0.7 & -4.0 \\
0 & -0.06\end{array}$ & $\begin{array}{l}0 \\
0.2-0.9 \\
0-0.05 \\
1.0-4.0 \\
0-0.3\end{array}$ & $\begin{array}{l}0 \\
0.1-0.6 \\
0.05-0.4 \\
0.9-7.0 \\
\text { Tr }-0.2\end{array}$ & $\begin{array}{c}4.1-6.9 \\
3.5-9.4 \\
0 \\
4.9-8.5 \\
1.8-2.8\end{array}$ & $\begin{array}{c}2.3-2.8 \\
5.1-6.3 \\
0 \\
\text { Up to } 11.9 \\
\text { Up to } 4.1\end{array}$ & $\begin{array}{l}0 \\
0 \\
0-0.02 \\
0.3-2.0 \\
0\end{array}$ & $\begin{array}{ll}0 & 0 \\
0 & -\mathrm{Tr} \\
0 & -0.05 \\
0.5-2.5 \\
0\end{array}$ \\
\hline
\end{tabular}


the diene metabolites, the following metabolites are included: E-2-ene and Z-2-ene, cis-3-ene and trans3-ene, 4-ene, 2-propyl-3-hydroxypentanoic acid, 2propyl-3-oxopentanoic acid, 2-propyl-4-hydroxypentanoic acid, 2-propyl-5-hydroxypentanoic acid and 2-propylglutaric acid. It is evident that both the number and the concentration of the single diene metabolites are increased if clinical side-effects are present. Drastically enhanced amounts were found in a case with fatal hepatic failure (6). Similar results were obtained in 4 other fatal cases, although the concentrations of the diene metabolites in plasma and urine were not so greatly elevated as in the patient cited, and the metabolic patterns were slightly different (12).

E-2.4-diene, diene/2, and diene/3 may be regarded as normal metabolic products, and the last one is always the most prominent doubly unsaturated metabolite. E-2-4-diene is sometimes missing, and when present, its concentration is always very low in normal patients. In contrast, the $4.4^{\prime}$-diene is thought to be abnormal due to its complete absence from children and adults treated without complications. Diene/4 was sporadically observed only in adults, and its enhanced formation in the presence of sideeffects and hepatotoxicity qualified this metabolite as possibly toxic.

\section{Discussion}

So far, we have detected a total of 5 doubly unsaturated metabolites of valproic acid. There are numerous possible isomers of these diene metabolites, which cannot be reliably differentiated and characterized by mass-spectrometry. To ensure the correct assignment of the two double bond positions, we therefore synthesized a series of doubly unsaturated derivatives of valproic acid (8). Only two of these synthetic compounds were found to be identical with native metabolites: 2(2-propenyl)-4-pentenoic acid (4.4'-diene) and E-2-propyl-2.4-pentadienoic acid (E-2.4-diene). The three other native diene metabolites are still non-defined with respect to the position and stereochemistry of the two double bonds. They are therefore termed diene $/ 2$, diene $/ 3$, and diene $/ 4$. However, their exact structures may be inferred from figure 8 , and these are illustrated in the metabolic scheme in figure 9. All possible diene derivatives containing a terminal double bond have been synthesized and the retention times of these compounds are smaller than those of the native metabolites, diene $/ 2$, diene $/ 3$ and diene $/ 4$.

Some of the synthetic products containing a terminal double bond have the same retention time as the me- tabolic products, i.e. 4-ene, 4.4'-diene, and E-2.4diene. Furthermore, it may be concluded from figure 8 , that

a) the two double bonds in the native diene $/ 2$, diene $/ 3$, and diene $/ 4$ metabolites are distributed in both carbon chains,

b) the possibility of a terminal double bond in these three metabolites can be excluded, and

c) only $3.3^{\prime}$-diene isomers (3-trans/3'-cis, 3-cis/3'cis, 3-trans/3'-trans) or 2.3'-diene isomers (2-trans/ 3'-trans, 2-cis/3'-cis, 2-cis/3'-trans, 2-trans/3'-cis) may be predicted.

This means that one double bond must be localized in $\Delta 3,4$ position of the metabolites diene $/ 2$, diene $/ 3$ and diene/4. A shift of the terminal double bond to the inner tertiary carbon atom is accompanied by an increase in retention time (see fig. 8). Therefore, the structure of diene $/ 4$ and also of diene $/ 3$ is assumed to be rather a $2.3^{\prime}$-diene than a $3.3^{\prime}$-diene. Since the 2-ene is the main metabolite of the mono-ene group, its function as a precursor is more plausible than that of the 3-ene, normally only of minor importance. Consequently, diene/2 might be assigned a 3.3'diene structure with the 3 -ene as precursor.

The formation of the E-2.4-diene is unusual in so far as the second double bond is introduced into the propenylic and not into the propylic group. In this connection, it should be noted that 2.4-pentadienoic acid is formed metabolically from 4-pentenoic acid (13).

The metabolic pattern of valproic acid metabolism in fatal hepatic failure is characterized by an increased formation of doubly unsaturated metabolites as exemplified in a patient (see tab. 3) (6). The 4.4'-diene is considered to be an abnormal metabolite, which is never found in patients without severe complications. Its formation seems to be always accompanied by the 4-ene, which may also be sporadically observed in normal patients (but not more than $0.05 \%)$. The toxic effects of the 4-ene are thought to be analogous to the features of Reye's syndrome induced in rats by 4-pentenoic acid (14). As the 2-ene (main metabolite of the mono-ene group) and the 3ene as well as the E-2.4-diene, diene/2, and diene/3 (main metabolite of the diene group) are normal and almost obligatory metabolites, the distinct appearance of the 4.4'-diene, the 4-ene, and the diene/4 in fatal hepatic damage $(6,12)$ may indicate a metabolite aberration, the cause of which is still unknown. The percentage distribution of the unsaturated metabolites was not unique in the fatal cases. Reversible valproic acid-induced side-effects (drowsiness, 


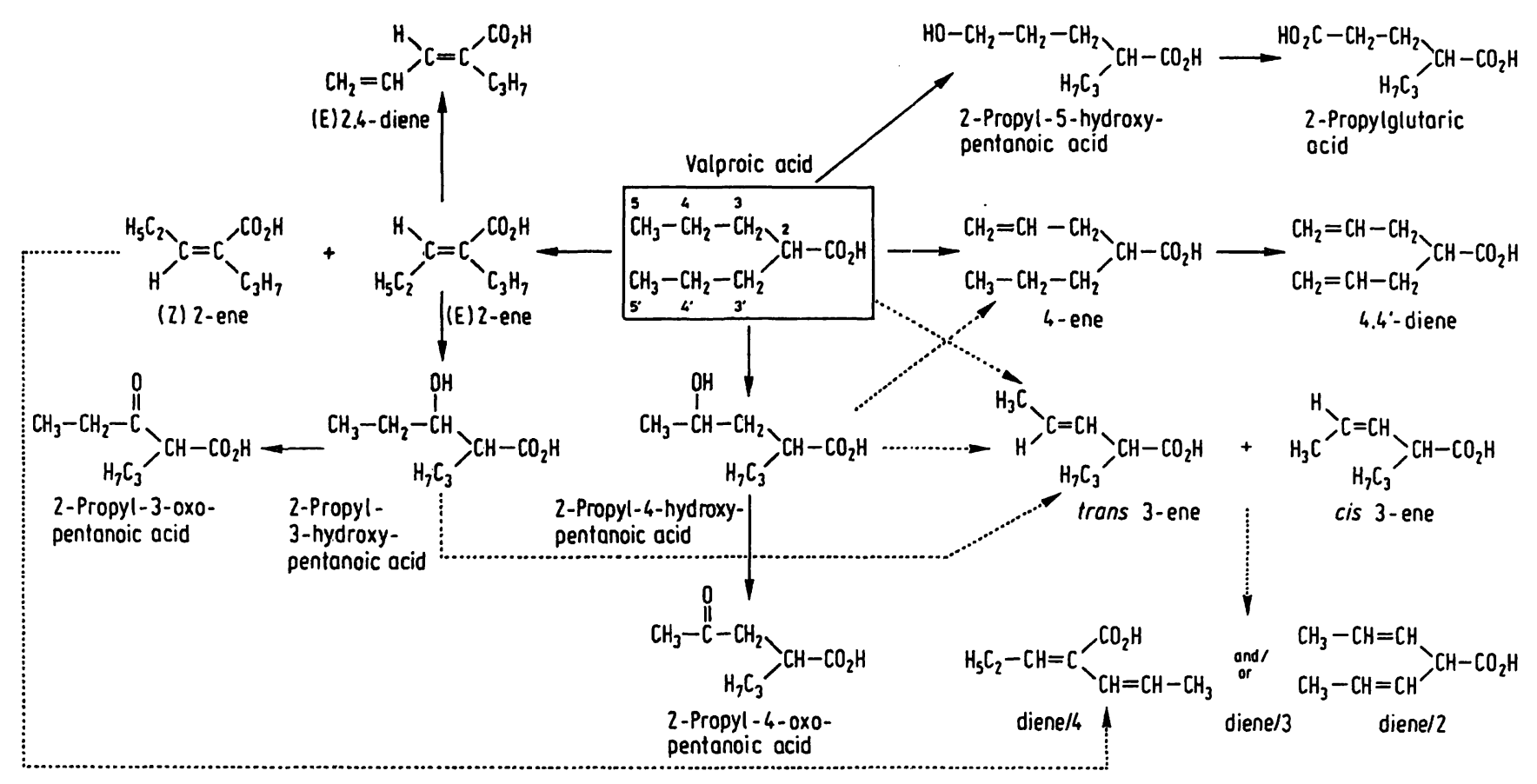

Fig. 9. Preliminary metabolic scheme of valproic acid metabolism.

lethargy, vomiting, anorexia etc.) are known, and laboratory data (moderate increase in blood ammonia and transaminases) indicate disturbed liver functions in association with a changed valproic acid metabolism. Preliminary results in such cases have demonstrated that increased urinary diene $/ 3$ might be indicative of a disturbed metabolic situation, if its urinary concentration is above the upper limit of $3 \%$ (valproic acid plus all found metabolites $=100 \%$ ) (12). In addition, both the 4-ene and the $4.4^{\prime}$-diene may be detected in traces.

It is very difficult to decide when valproic acid therapy should be discontinued, because conventional liver function tests do not seem to predict hepatotoxicity. On rare occasions, valproic acid may initiate a type of liver failure that almost always leads to the death of the patient. The presence of side-effects associated with clinical signs of liver or pancreatic dysfunction, together with the appearance of the 4-ene, and the $4.4^{\prime}$-diene, and increased excretion of the diene $/ 3$ are an indication that valproic acid treatment should be discontinued. One group of patients has been identified, which is particularly at risk; these are strongly retarded children with intractable epilepsy on multiple antiepileptic drug therapy. Attention is imperative especially during the first 6 months after onset of valproic acid therapy.

\section{References}

1. Wilder, B. J. \& Bruni, J. (1981) In: Seizure disorders: A pharmacological approach to treatment, Chapter 7, Raven Press New York.

2. Zimmerman, H. J. \& Ishak, K. G. (1982) Hepatology 2, 591-597.

3. Valproate Symposium of the International Liga against Epilepsy (September, 27, 1983 at Washington), to be published in Epilepsia 1984

4. Gram, L. (1983) In: Chronic toxicity of antiepileptic drugs (Oxley, J., Janz, D. \& Meinardi, H., eds.). p. 69-77, Raven Press New York.

5. Delgado-Escueta, A. V., Treiman, D. M. \& Walsh, G. O. (1983) N. Engl. J. Med. 308, 1576.

6. Kochen, W., Schneider, A. \& Ritz, A. (1983) Eur. J. Pediatr. $141,30-35$.

7. Kochen, W. \& Scheffiner, D. (1980) In: Antiepileptic Therapy: Advances in Drug Monitoring (Johannessen, S. I., Morselli, P. L., Pippenger, C. E., Richens, A., Schmidt, D. \& Meinardi, H., eds.), pp. 111-120, Raven Press, New York.

8. Klemens, M. (1980) Diplomarbeit Universität Heidelberg.

9. Barnett, R. N. (1947) J. Amer. Med. Assoc. 135, 28-30.

10. Conrad, M. \& Bischoff, C. A. (1880) Liebigs Ann. Chemie 204, 138.

11. Schlosser, M. (1970) In: Topics in Stereochemistry (Eliel, E. L. \& Allinger, N. L., eds.) Vol. 5, p. 1, Springer-Verlag Berlin-Heidelberg-New York.

12. Kochen, W. \& Sprunck, H. P. (1983) 57. Jahrestagung der Dtsch. Ges. für Neurologie und Jahrestagung der Dtsch. Sektion der Intern. Liga gegen Epilepsie, Mannheim, October, 13th and 14th. To be published 1984 in: Epilepsie 1983, (Hallen, O. \& Meyer-Wahl, J. G., eds.), Georg Thieme Verlag Stuttgart.

13. Holland, P. C., Senior, A. E. \& Sherrat, H. S. A. (1973) Biochem. J. 13.6, 173-184.

14. Glasgow, A. M. \& Chase, P. (1975) Pediatr. Res. 9, 133138.

Prof. Dr. W. Kochen

Klinikum der Universität Heidelberg

Kinderklinik

Im Neuenheimer Feld 150

D-6900 Heidelberg 


\section{$\therefore \ldots$.}

